\title{
Reliable long-term performance assessment of commercial photovoltaic modules tested under field conditions over 5 years
}

Cite as: J. Renewable Sustainable Energy 11, 063501 (2019); https://doi.org/10.1063/1.5128171

Submitted: 17 September 2019 . Accepted: 02 December 2019 . Published Online: 31 December 2019

Peter Kraus (D), Cyriac Massué (D), Saskia Heumann (D), and Robert Schlögl

COLLECTIONS

F This paper was selected as Featured
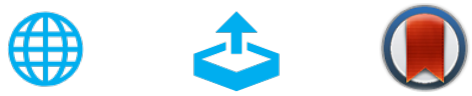

\section{ARTICLES YOU MAY BE INTERESTED IN}

Evaluation of solar module equivalent models under real operating conditions-A review Journal of Renewable and Sustainable Energy 12, 012701 (2020); https:// doi.org/10.1063/1.5099557

Prediction of the impact of support structures on the aerodynamic performance of large wind farms

Journal of Renewable and Sustainable Energy 11, 063306 (2019); https://

doi.org/10.1063/1.5120602

Producing wind energy at the cost of biodiversity: A stakeholder view on a green-green dilemma

Journal of Renewable and Sustainable Energy 11, 063303 (2019); https://

doi.org/10.1063/1.5118784

\section{Scilight}




\title{
Reliable long-term performance assessment of commercial photovoltaic modules tested under field conditions over 5 years
}

Cite as: J. Renewable Sustainable Energy 11, 063501 (2019); doi: 10.1063/1.5128171

Submitted: 17 September 2019 - Accepted: 2 December 2019 .

Published Online: 31 December 2019

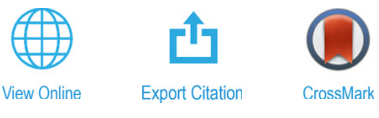

Peter Kraus, $^{1, a)}$ (D) Cyriac Massué,, ${ }^{1,2}$ (D) Saskia Heumann, ${ }^{2}$ (D) and Robert Schlögl ${ }^{1,2}$

AFFILIATIONS

${ }^{7}$ Fritz-Haber-Institut der Max-Planck-Gesellschaft, Anorganische Chemie, Faradayweg 4-6, 14195 Berlin, Germany

${ }^{2}$ Max-Planck-Institut für Chemische Energiekonversion, Heterogene Reaktionen, Stiftstr. 34-36, 45470 Mülheim a. d. Ruhr, Germany

${ }^{a)}$ Electronic mail: kraus@fhi-berlin.mpg.de

\begin{abstract}
Due to their scalability and global abundance of sunlight, photovoltaic panels are a promising option as a renewable energy source. Implementation of photovoltaic technologies on a large scale requires a careful business-case assessment, aimed at the selection of the technological option most appropriate for the local conditions in terms of long-term performance. For this purpose, five types of modules representative of current options on the market were tested under field conditions for five years at a test facility in Germany. The degradation rates of module performance were computed from the obtained photovoltaic power normalized by both recorded and modeled solar irradiance. The results emphasize the relevance of using modeled irradiance data in addition to recorded solar irradiance in order to extract reliable degradation rates. The available methodological tools still have to be adapted to every dataset for the most accurate result. Eventually, robust degradation rates were extracted from experimental power data, based on modeled clear-sky irradiance, and a combination of aggregation and regression strategies. The results show distinctive degradation behaviors of the five available commercial photovoltaic modules in response to the local conditions.
\end{abstract}

Published under license by AIP Publishing. https://doi.org/10.1063/1.5128171

\section{INTRODUCTION}

Identifying the correct choice among the many available commercial photovoltaic (PV) modules relies on an accurate prediction of the projected energy yield and the cost of investment. As a broad variety of PV technologies exhibiting different performances is reaching market maturity, important parameters that would enable reliable business projections are often missing. For instance, the specification sheets of commercial modules commonly report the expected performance and efficiency under standard testing conditions (STCs). ${ }^{1}$

The efficiency of PV panels can vary significantly with environmental parameters. The performance of the semiconductor material itself has a major effect on the overall performance of a PV plant under field conditions. In order to reflect such effects, specification sheets often report correction factors, including the correction coefficients of current, voltage, and power, which account for variations in module temperature. However, studies have shown that an accurate prediction of the field performance of a PV module needs to take into account the influence of a much larger range of parameters. The effects of irradiance intensity, spectral composition of irradiance, and angle-ofincidence in addition to the effect of module temperature have recently been studied using several types of PV modules. ${ }^{2}$ All the named parameters have a significant effect on module performance, and the modules are affected to a different degree depending on their composition. Therefore, specification sheets should include the correction factors for a broader range of operating parameters, accounting for the specific dependency of each PV technology on a broad range of operating conditions ${ }^{2}$ and associated failure modes. This will allow for informed decisions on the most appropriate PV technology based on local operating conditions.

Currently, module technologies based on crystalline silicon dominate the worldwide market with a share of $95 \%-97 \%{ }^{3,4}$ Within this family, multi- or polycrystalline (poly-Si) devices represent $65 \%$ of the market share. ${ }^{4}$ This is mainly due to lower production costs, ${ }^{5}$ despite their lower efficiencies compared to single-crystal based Si technologies. ${ }^{6}$ Degradation mechanisms of these long established devices include discoloration of the encapsulation material ${ }^{7}$ and development of cracks ${ }^{8}$ and hot spots. ${ }^{9}$ Some degradation mechanisms, such as electrochemical degradation ${ }^{10}$ and leakage currents linked to silver paste discoloration, ${ }^{11}$ are strongly influenced by environmental conditions and have been investigated only recently. 
Thin-film solar cells have emerged in the 1990s as the second generation of solar cells, with the promise of reduced production costs, lower weight, and mechanical flexibility allowing for a broader range of applications. Despite reaching efficiencies comparable to crystalline silicon, thin-film modules have not yet been able to conquer the PV market with a sub-10\% market share since $2012 .{ }^{4}$ The complex manufacturing and assembly of thin-film modules make them more prone to the formation of hot spot shunts. ${ }^{12}$ Depending on the materials used, specific degradation mechanisms have also been reported. Amorphous silicon (a-Si) thin-film cells have appeared as material-efficient alternatives to crystalline silicon, avoiding the use of more toxic thin-film materials. However, these cells suffer from the partly reversible Staebler-Wronski degradation mechanism, where light-induced defects lower the carrier lifetime. ${ }^{13}$ Thinner films are more resilient toward the Staebler-Wronski degradation mechanism, but come with lower efficiencies.

A proposed solution is to adopt tandem or triple-junction assemblies. In tandem cells, a microcrystalline silicon base layer is combined with an amorphous silicon top layer, yielding a so-called micromorph silicon cell ( $\mu \mathrm{m}-\mathrm{Si})$. This allows for low manufacturing costs, a better resilience to light-induced degradation, ${ }^{13-15}$ and better conversion efficiencies. ${ }^{16}$ Other upcoming thin-film technologies include cadmium telluride (CdTe) and copper indium gallium diselenide $\left(\mathrm{CuIn}_{x} \mathrm{Ga}_{1-x}\right.$ $\mathrm{Se}_{2}$, CIGS). A central challenge in CdTe cells is the harmful diffusion of copper from back contacts, especially at higher temperatures. ${ }^{17}$ In addition, the creation of a back-contact barrier via CdTe oxidation in damp environments has been reported, but remains little studied. ${ }^{18}$ Finally, the degradation mechanisms in CIGS panels have been little studied. CIGS has been reported to undergo degradation due to shunt path formation linked to light- and heat-induced migration of alkali dopants. ${ }^{19}$

A third generation of solar cells, including organic and dyesensitized cells, is only emerging as a possible alternative and remains to be extensively studied under field conditions once commercial products become available.

Accelerated degradation tests as proposed by the IEC cover only some aspects of PV panel degradation. The IEC 61215 and IEC 61646 tests can be considered "infant mortality" tests. ${ }^{20}$ For the purpose of reliable business modeling, solar panels have to be tested under field conditions. Such tests have to be conducted on a global scale in order to integrate a broad range of relevant conditions into a unified model. For this purpose, great efforts have been dedicated to the aggregation of degradation rates from testing facilities present all over the world. Openly and freely available data are available from locations such as Australia (Desert Knowledge Australia Solar Centre) or the UK (University of Sheffield), but most performance data remain proprietary. To the best of our knowledge, no such data are available for northern Germany.

The results of such data analyses have for instance highlighted the sensitivity of some PV technologies to hotter climate. ${ }^{21}$ The accuracy of the reported degradation rates suffers from operational uncertainties such as sensor drift or degradation. In order to address this issue, researchers from the National Renewable Energy Laboratory (NREL) and SunPower Corporation have recently proposed a methodology aimed at extracting performance and degradation rates from operational PV data. ${ }^{22}$ In order to circumvent uncertainty factors including unreliable data from irradiance and temperature sensors, the methodology is based on modeled clear-sky irradiance data combined with a robust year-on-year rate calculation. This methodology has been recently validated using real-world PV data from tropical climate in Singapore, ${ }^{23}$ as well as on a fleet-scale analysis of residential and nonresidential systems in the United States. ${ }^{24}$

We demonstrate the successful independent application of this "clear-sky methodology" to a PV field-testing facility installed at the Max-Planck-Institute of Chemical Energy Conversion (MPI-CEC) in Mülheim an der Ruhr, Germany. The PV panels installed at MPICEC are part of a test facility assessing the reliability of various energy storage options ranging from commercial batteries to chemical energy storage via electrolytic water splitting. While the focus of the facility is on the study of the energy storage options, the performance of the various installed solar panels exhibited major discrepancies over time, hinting at distinct sensitivities to the on-site conditions and resulting degradation behavior. These observations prompted the assessment of PV degradation from the various panels. In this process, issues with the reliability of the irradiance sensor could be successfully circumvented via the clear-sky methodology. Thus, a reliable comparison of the PV panel performance could be obtained in addition to demonstrating the effectivity of the tools developed by the NREL and SunPower researchers in the framework of the clear-sky methodology.

\section{METHODOLOGY}

\section{A. PV test plant and data acquisition}

The experimental data analyzed in this work are recorded at the Max Planck Institute for Chemical Energy Conversion (MPI-CEC) located in Mülheim an der Ruhr (NRW, Germany), $90 \mathrm{~m}$ above the sea level. The PV test facility is situated on top of a four-storey building, at a height of about $15 \mathrm{~m}$, at a longitude of $6.887^{\circ} \mathrm{E}$ and a latitude of $51.418^{\circ} \mathrm{N}$. The facility operates continuously since September 2013.

The plant includes 5 different inorganic PV technologies as shown in Fig. 1. Commercial modules representative of the main available technologies are installed: micromorph thin film silicon $(\mu \mathrm{m}-\mathrm{Si})$, cadmium telluride (CdTe), copper indium gallium selenium (CIGS), polycrystalline silicon (poly-Si), and amorphous silicon (a-Si). The plant is designed to produce about $10 \mathrm{~kW}$ in total. Accordingly, for each module type, the equivalent of approximately $2 \mathrm{~kW}$ is installed. The relevant properties of each panel type are summarized in Table I. All panels are tilted by $20^{\circ}$ and directed to the south. For each module type, a SMA Sunnyboy 2000HF-30 DC/AC converter is installed. Data are recorded once a second and monitored by a LogMessage data logger from Delphin. A pyranometer from Kipp\&Zonen is concomitantly measuring the in-plane irradiance. Two temperature sensors are installed for each module type, one at the front and the other at the rear of the panel. Simultaneously, meteorological data such as atmospheric pressure, temperature, humidity, wind speed, and wind direction are recorded using a Vaisala Weather Transmitter WXT520.

\section{B. Data analysis}

All data analysis is performed using python-3.7.2, with matplotlib-3.0.2 used for graphing and pandas-0.24.1 used for CSV file processing. Additionally, the libraries pvlib-0.5.2 and rdtools-1.2.2 are used for filtering, aggregation, regression, and clear-sky modeling. All scripts and data required to reproduce figures in the current work are included in the supplementary material. A graphical overview of the three stages in the data processing sequence is shown in Fig. 2, with a 


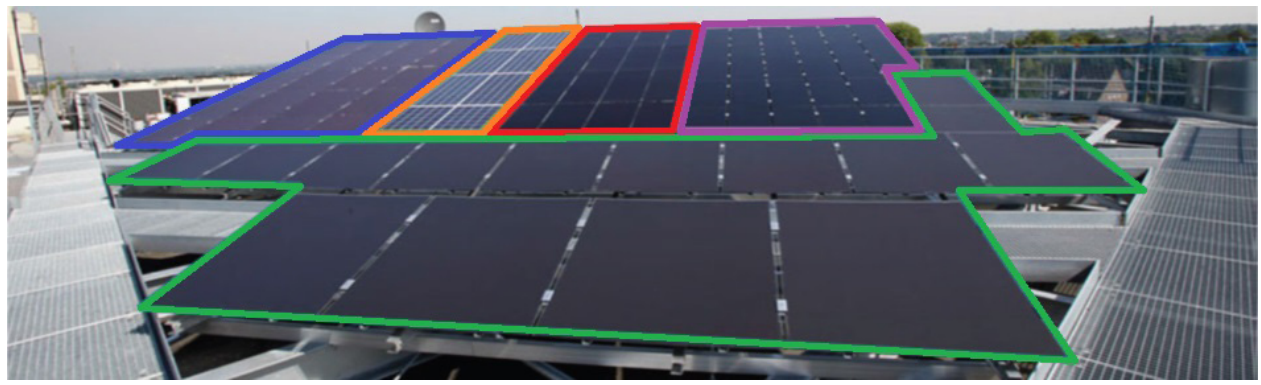

FIG. 1. Overview of the PV site in Mülheim an der Ruhr. Panels highlighted according to the type: $\mu \mathrm{m}-\mathrm{Si}$ (green), CdTe (purple), CIGS (blue), poly-Si (orange), and a-Si (red).

TABLE I. PV module specifications according to the manufacturers: total area, number of modules, efficiency, STC rated power per module $\left(P_{\mathrm{mpp}}\right)$, current and voltage at rated power $\left(I_{m p p}\right.$ and $\left.V_{\text {mpp }}\right)$, short-circuit current $\left(I_{s c}\right)$, open-circuit voltage $\left(V_{\text {oc }}\right)$, and power temperature coefficient $(\gamma)$.

\begin{tabular}{|c|c|c|c|c|c|}
\hline Type & $\mu \mathrm{m}-\mathrm{Si}$ & $\mathrm{CdTe}$ & CIGS & poly-Si & $\mathrm{a}-\mathrm{Si}$ \\
\hline Manufacturer & Masdar & Calyxo & Avancis & Trina & Masdar \\
\hline Module type & MPV-135-M-Sama1 & $\mathrm{M}-\mathrm{CX} 3$ & PowerMax & PC05A & MPV100-S-Sama1 \\
\hline Total area $\left(\mathrm{m}^{2}\right)$ & 21.45 & 20.16 & 16.86 & 13.10 & 28.60 \\
\hline Number of modules & 15 & 28 & 16 & 8 & 20 \\
\hline Efficiency (\%) & 9.4 & 10.8 & 11.4 & 16.1 & 7.0 \\
\hline $\mathrm{P}_{\mathrm{mpp}}(\mathrm{W})$ & 135.0 & 77.5 & 130.0 & 255.0 & 100.0 \\
\hline $\mathrm{I}_{\mathrm{mpp}}(\mathrm{A})$ & 1.21 & 1.83 & 2.87 & 8.37 & 1.34 \\
\hline $\mathrm{V}_{\mathrm{mpp}}(\mathrm{V})$ & 111.8 & 43.0 & 45.3 & 30.5 & 100.0 \\
\hline $\mathrm{I}_{\mathrm{sc}}(\mathrm{A})$ & 1.41 & 2.16 & 3.23 & 8.88 & 1.58 \\
\hline $\mathrm{V}_{\mathrm{oc}}(\mathrm{V})$ & 142.2 & 59.6 & 60.2 & 38.1 & 96 \\
\hline Total power $(\mathrm{W})$ & 2025 & 2170 & 2080 & 2040 & 2000 \\
\hline$\gamma\left(\% \mathrm{~K}^{-1}\right)$ & -0.27 & -0.25 & -0.39 & -0.41 & -0.20 \\
\hline
\end{tabular}

flow chart for obtaining the performance ratios from recorded data shown in Fig. 3.

Prior to data processing, the raw data from the plant are exported with a $15 \mathrm{~min}$ frequency (internal database ID 47472). The relevant time series are merged into a single CSV file (see the supplementary material). The retained columns include the timestamp, the instant power $P(\mathrm{~W})$, and temperature $T_{\text {cell }}\left({ }^{\circ} \mathrm{C}\right)$ of each panel and the ambient air temperature $T_{\text {air }}\left({ }^{\circ} \mathrm{C}\right)$ and wind speed $v_{\text {wind }}\left(\mathrm{m} \mathrm{s}^{-1}\right)$, the pyranometer irradiance $G\left(\mathrm{~W} \mathrm{~m}^{-2}\right)$, and the total energy generated by each panel type since installation $E(\mathrm{kWh})$. The timestamps are corrected to UTC, the rows deduplicate, and any rows with missing data are discarded.

All performance ratios shown in Fig. 3 are calculated using the NORMALIZE_WITH_PVWATTS routine in rdtools. This routine implements

\section{Filtering Aggregation Regression}

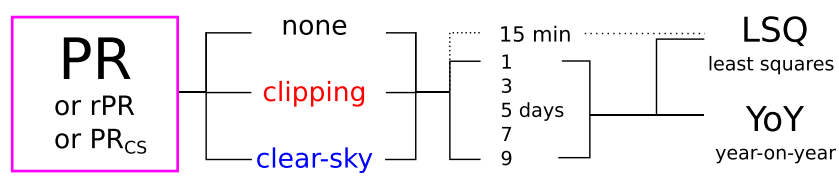

FIG. 2. A schematic diagram of the data processing pipeline: filtering, aggregation, and regression.

$$
\mathrm{PR}=\frac{P}{P_{\text {rated }} \frac{G}{1000 \mathrm{~W} \mathrm{~m}^{-2}}\left(1+\gamma\left(T_{\text {cell }}-25^{\circ} \mathrm{C}\right)\right)},
$$

where $P_{\text {rated }}$ is the rated power of the panel at STC $\left(1000 \mathrm{~W} \mathrm{~m}^{-2}\right.$ irradiance and $\left.25^{\circ} \mathrm{C}\right), \gamma$ is the power temperature coefficient of the panel, $T_{\text {cell }}$ is the measured panel temperature, $P$ is the measured panel output, while $G$ is the measured pyranometer irradiance, unless noted otherwise.

\section{Filtering}

The first step in the data processing pipeline (Fig. 2) is the filtering step. In addition to the unfiltered performance ratio (PR) data, two different filtering approaches are used in the current work: clipping filter used in conjunction with PR and rPR and clear-sky filter used with $\mathrm{PR}_{\mathrm{cs}}$. Both filtering methods share the following three masks:

1. a nonzero mask, where the normalized performance ratio is enforced to be positive,

2. a temperature mask, where $T_{\text {cell }}$ is enforced to be within the $-50^{\circ}-110^{\circ}$ interval,

3. an irradiance mask, which enforces $\mathrm{G}$ within the $200-1200 \mathrm{~W} \mathrm{~m}^{-2}$ interval. 


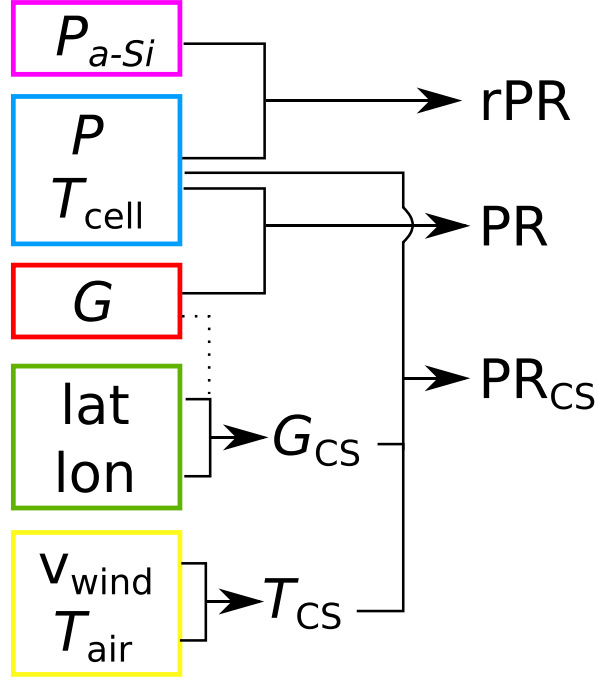

FIG. 3. Flowchart for calculating the conventional performance ratio (PR), performance ratio relative to the a-Si panel (rPR), and a clear-sky performance ratio $\left(\mathrm{PR}_{\mathrm{cs}}\right)$ from measured data.

On average, the nonzero mask removes $\sim 51 \%$ of the datapoints, the temperature mask removes almost no points, and the irradiance mask excludes $\sim 79 \%$ of the data.

In the clipping filter, an additional mask is applied. This mask excludes data with a normalized performance ratio below 0.01 , as well as all data with a normalized performance ratio higher than $99 \%$ of the 98th quantile in the dataset. This mask is intended to remove inverter clipping, which supposedly occurs on highly producing days for panels with a high $\mathrm{DC} / \mathrm{AC}$ ratio. ${ }^{22}$ The mask removes $\sim 14 \%$ of the data.

In the clear-sky filter, this clipping mask is not used and a clearsky mask is applied instead. First, a clear-sky irradiance is calculated from the timeseries data and the geographical latitude and longitude (see Fig. 3). The resulting timeseries corresponds to the expected irradiance at that location and time under ideal, sunny conditions and hence the name "clear-sky." This clear-sky irradiance is then rescaled to match the pyranometer irradiance data $(G)$. Alternatively, the timeseries of power data from a nondegrading panel can be used, as discussed below. In the clear-sky mask, all points where $G$ falls outside of a certain trust interval from $G_{\mathrm{CS}}$ are excluded. Trust intervals in the range of $5 \%-20 \%$ are investigated. Jordan et al. recommended $20 \%$, ${ }^{22}$ while the default value in rdkit-1.2.2 is $15 \%$. The rescaled clear-sky irradiance $G_{C S}$ is also used instead of $G$ in the irradiance mask above.

The temperature mask is also modified: instead of the measured panel temperature, a modeled panel temperature $T_{\mathrm{CS}}$ is calculated from the ambient air temperature and wind speed data in addition to the $G_{\mathrm{CS}}$ calculated above. An inverter clipping mask is not applied in the clear-sky filter.

To obtain an estimate for the errors in the degradation rates due to the pyranometer irradiance, the measured pyranometer data can be replaced by the measured data from a different source. As a second pyranometer was not available, the power obtained from the a-Si panels is chosen as a reference system as they exhibit the most stable degradation behavior, regardless of the filtering (see below). To achieve this, $G$ in Eq. (1) is replaced with $G_{\mathrm{a}-\mathrm{Si}}$ from Eq. (2),

$$
G_{\mathrm{a}-\mathrm{Si}}=\frac{P_{\mathrm{a}-\mathrm{Si}}}{P_{\text {rated }} \frac{1}{1000 \mathrm{~W} \mathrm{~m}^{-2}}\left(1+\gamma_{\mathrm{a}-\mathrm{Si}}\left(T_{\text {cell }}-25^{\circ} \mathrm{C}\right)\right)} .
$$

This allows us to obtain a relative performance ratio (rPR), which is essentially a performance ratio normalized by the performance ratio of the a-Si panel, and thus is independent of the pyranometer data. This approach can be combined with the clear-sky method, to completely exclude the pyranometer data from the data processing. However, the use of a-Si based data also adds additional sources of errors, as we cannot be certain that the a-Si panels do not suffer from significant degradation. Furthermore, the spectral response of the a-Si modules is likely to differ from that of the other module types due to the different materials and composition of the panels. With this in mind, the rPR data series is used as a qualitative tool for error estimation only.

The effects of the various filtering approaches are shown in Fig. 4. The unfiltered $15 \mathrm{~min}$ PR data highlight two periods of unreliable data with a high occurrence of $P R$ values $\geq 1.0$ : a first event in 2014-2016 as well as a second event starting in 2018. When the pyranometer irradiance $G$ is replaced with $G_{\mathrm{a}-\mathrm{Si}}$ based on Eq. (2), the resulting rPR is sensible in the 2014-2016 period, confirming it is caused by the pyranometer data. The horizontal line at $\sim 0.5$ in the $\mathrm{rPR}$ results is
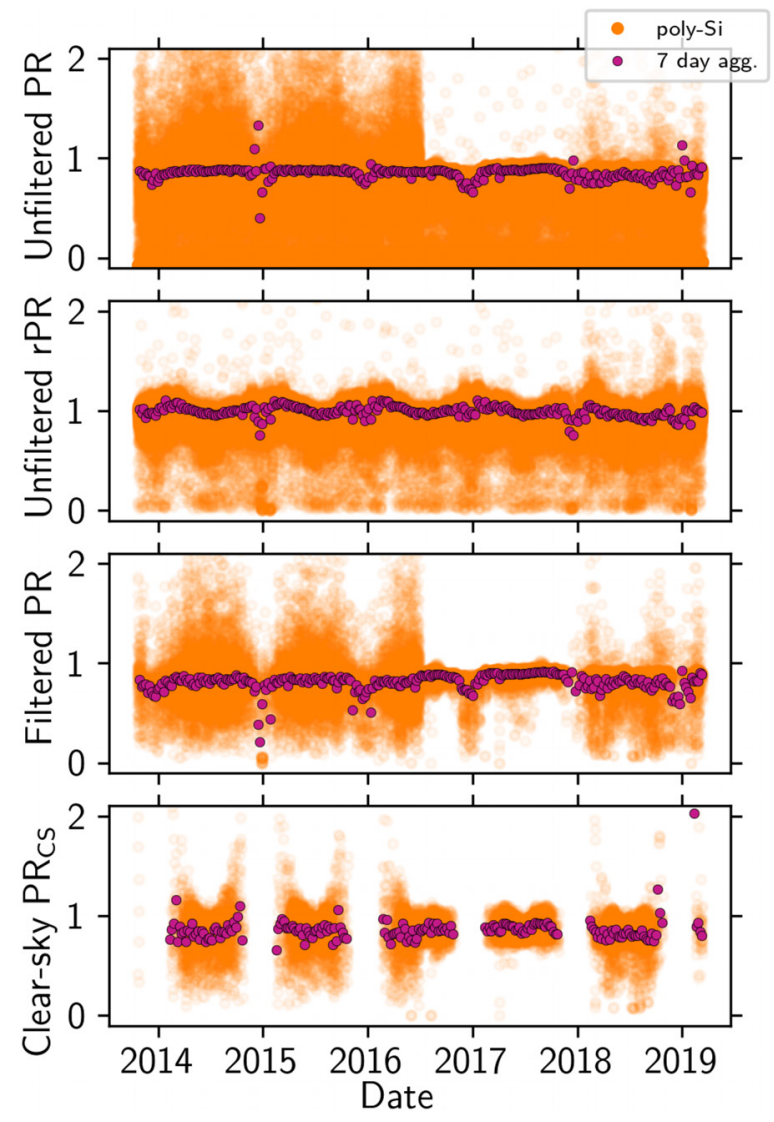

FIG. 4. Unfiltered PR and rPR data, as well as data filtered using the clipping and clear-sky filters (orange dots). Aggregated data (purple dots) are also shown. For a side-by-side comparison with other panel types, see Fig. S7. 
caused by near-zero values in the $G_{\mathrm{a}-\mathrm{Si}}$ timeseries, which can be safely filtered out. Notably, the clipping filter does not help with the sensor issues between 2014 and 2016, as such cannot be recommended. The clear-sky filter, here applied with a trust interval of $20 \%$ following the recommendation of Jordan et al., ${ }^{22}$ performs reliably in the summer months, but cuts out nearly all data during the winter periods.

\section{Aggregation}

The data aggregation is performed using the AGGREGATION_INSOL routine in rdtools. The aggregation is carried out on the performance ratio time series, which is weighted by the associated insolation ( $I=G \Delta t$, in $\mathrm{J} \mathrm{m}^{-2}$ ), according to the following equation:

$$
\operatorname{PR}(p)=\frac{\sum \operatorname{PR} I}{\sum I},
$$

where the resulting performance ratio is aggregated in periods of length $p$ and the sums run over all datapoints within $p$.

The effects of aggregation on the performance ratios are shown in Fig. 5. The 2014-2016 period is significantly less noisy even with a 1 day aggregation interval (clear dots), but the scatter in the winter periods remains for all panel types, including the two panel types shown. Aggregation periods above 3 days can be recommended, especially in conjunction with the year-on-year regression method (see below). The 7 day period (purple dots) will be used throughout this work for consistency with the study by Jordan et al. ${ }^{22}$

\section{E. Regression}

Two regression methods are applied here: (i) an ordinary least squares regression (LSQ), where all data are fitted to a single

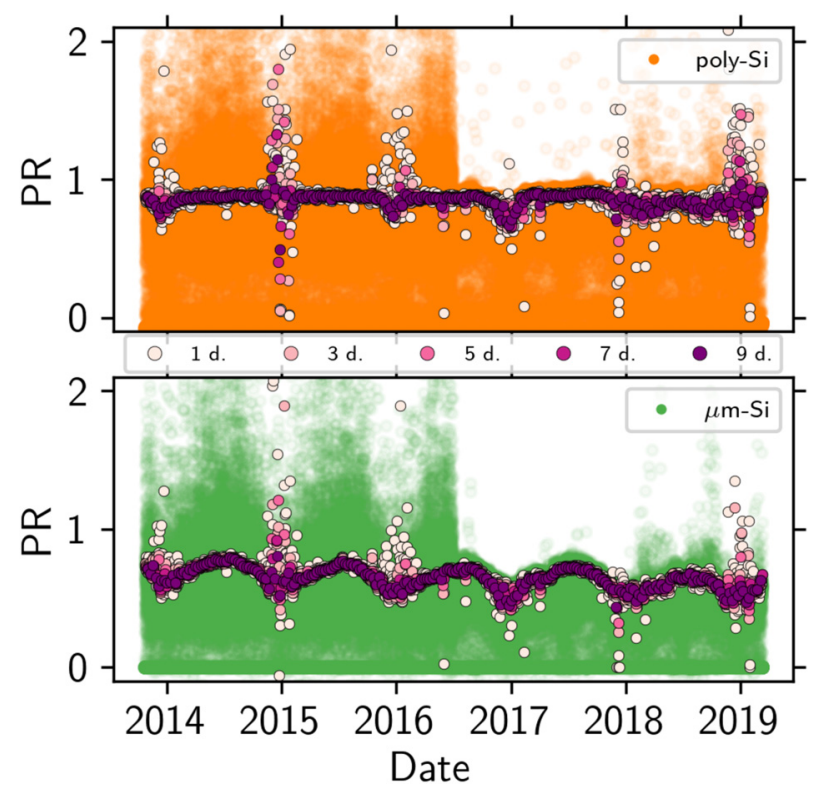

FIG. 5. Demonstration of the effect of data aggregation for PR values over various time periods between 1 day (clear dot) and 9 days (purple dots) for poly-Si (top) and $\mu \mathrm{m}-\mathrm{Si}$ (bottom) panels. expression, and (ii) a year-on-year regression (YoY), where a set of degradation rates is computed for aggregated periods separated by exactly one year. Both approaches are used as implemented in rdtools-1.2.2, with a confidence interval of $68.2 \%$.

In addition to the significantly better robustness of the YoY regression with respect to other parameters, the method allows for a deeper statistical analysis by evaluating the histograms of the year-on-year degradation rates (see the supplemental material). Additionally, it is possible to plot the time evolution of the degradation rate as shown in Fig. S6, which is useful in identifying periods of poor panel performance.

\section{RESULTS AND DISCUSSION}

A first performance assessment of the five PV module types is based on energy generated by each module type over five years. The results shown in Fig. 6 are normalized to a nominal installed rated power of $2000 \mathrm{~W}$ for better comparability. While the most established technologies based on amorphous silicon (a-Si) and polycrystalline silicon (poly-Si) exhibit the highest and rather similar output, the panels based on CIGS and CdTe clearly fall behind in output over the years. The worst performer is the micromorph silicon panel $(\mu \mathrm{m}-\mathrm{Si})$. Between 2014 and 2019, the $\mu \mathrm{m}$-Si panel produced 21\% less energy than the a-Si and poly-Si panels. This behavior cannot be explained by temperature effects alone, as the $\mu \mathrm{m}$-Si modules recorded the lowest mean $\left(13.2^{\circ} \mathrm{C}, 0.5^{\circ} \mathrm{C}\right.$ lower compared to the other module types) and median $\left(11.1^{\circ} \mathrm{C}\right)$ temperature over the 5 -year period. Such a clear discrepancy between the various panel types hints at degradation phenomena affecting the panels in distinctive ways.

In order to uncover such suspected degradation phenomena, the performance ratio (PR) needs to be extracted from each panel's power data [Eq. (1)]. Usually, the PR is based on the real measured power, irradiance, and temperature data. ${ }^{2}$ However, a frequent bias in degradation rates calculated from real temperature and irradiance data has been previously highlighted. ${ }^{22}$ Sensors have to be frequently calibrated and checked for degradation. In our case, the quality of the PR data calculated on the basis of the real measured solar irradiance and temperature is affected by an obvious sensor malfunction (see Figs. 4 and 5). While the temperature sensors distributed over the different module

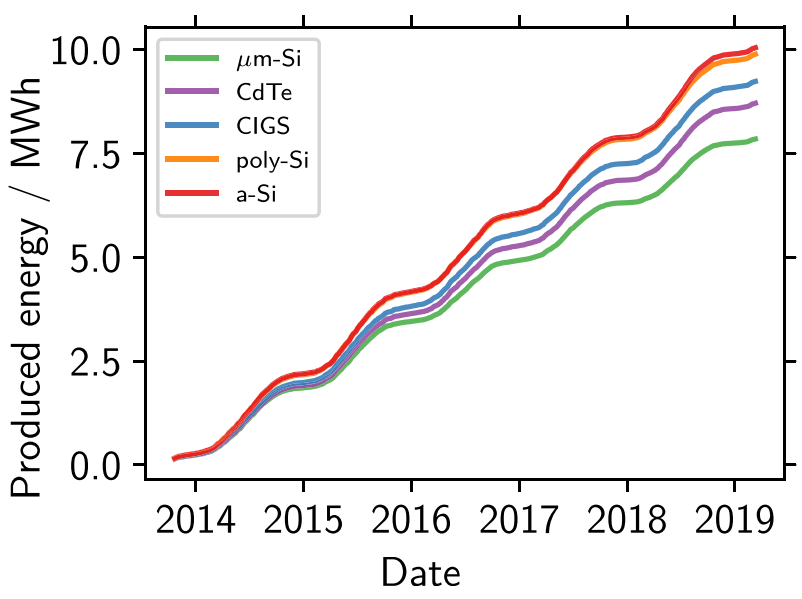

FIG. 6. Total energy output from the various installed PV panel types, normalized to a total maximum rated power of $2000 \mathrm{~W}$ per panel type. 
types produced rather consistent datasets, the single pyranometer produced inconsistent results. The pyranometer measurements are affected right from the start of the measurement by a clogged filter, responsible for filtering the air exchange within the pyranometer glass dome. With a clogged filter, humidity can accumulate within the glass dome of the pyranometer, giving rise to droplet formation on the inside. Such droplets are likely responsible for solar irradiance values randomly distributed around a central value, which is also lower than the real value due to absorption and scattering by the condensed water. After 29th of June 2016, when the pyranometer sensor was repaired, the qualitative improvement in the PR dataset is obvious, with PR values within the expected range of $\leq 1.0$.

Despite the sensor malfunction, a clear progressive drift toward lower PR values is visible for the $\mu \mathrm{m}$-Si panels in comparison to poly-Si panels in the data shown in Fig. 5. This confirms the importance of studying technology-specific degradation phenomena of the solar panels on the Mülheim-site. Nonetheless, the uncertainty arising from the irradiance sensor malfunction over the first two years hinders the determination of reliable degradation rates, which are needed for a more precise comparison of the long-term performance of various panel types.

In order to address sources of uncertainty such as sensor malfunctions, which affect the assessment of long-term performance of PV panels, researchers at the National Renewable Energy Laboratory (NREL) have recently developed a methodology aimed at enhancing reliability and robustness of the data processing. ${ }^{22,25,26}$ The goal of the project is to circumvent most sources of experimental error by calculating the performance ratios of a PV system based on modeled, rather than on-site measured irradiance and temperature. This clear-sky normalization yields a set of performance ratios, here denoted $\mathrm{PR}_{\mathrm{CS}}$, which should improve the accuracy of the calculated degradation rates. The methodology is implemented in a set of open-source Python libraries designed for the analysis of PV timeseries data. ${ }^{27}$ We applied the proposed three-stage methodology to our dataset, by filtering the 15 min data, aggregating it to longer periods, and then performing regressions to identify a reliable set of annual degradation rates.

\section{A. Effect of aggregation and regression on unfiltered PRs}

The measured performance ratios (PRs) are aggregated over various time periods (1-9 days). In principle, a 1 day period is sufficient to calculate the year-on-year regression, but longer periods are more effective at reducing the year-on-year variance. However, longer aggregation periods also significantly reduce the number of datapoints in the aggregated timeseries.

The effects of such aggregation on the degradation rates are shown in Fig. 7 for all five panel types. Two regression methods are compared: the ordinary least squares (LSQ) regression (gray) and the year-on-year (YoY) method (colour). The LSQ and YoY methods are affected differently by the aggregation time interval. While all YoYderived degradation rates are within the confidence interval of one another for all panel types, the LSQ-derived rates are inconsistent with aggregation time intervals below 5 days. Detailed results are shown in Table S1.

Figure 7 also shows that consistent and sensible degradation rates can be obtained from the measured data, without any filtering, even though the pyranometer measurement is clearly unreliable, as shown in Fig. 5. Alternative methods of correcting pyranometer data are discussed below.

In terms of panel performance, the aggregated PR of the consistently performing poly-Si panels (see Fig. 5) has a flat trend over the whole year, except around the darkest time of the year around the winter solstice. The aggregated PR of $\mu \mathrm{m}-\mathrm{Si}$ shows a higher seasonal dependence by fluctuating between a summer solstice maximum and a winter solstice minimum. This behavior of the $\mu \mathrm{m}$-Si panels is in line with previous reports on their seasonally dependent performance, as opposed to the more stable behavior of crystalline Si panels. ${ }^{28}$ This can be attributed to the seasonal changes in the composition of the solar spectrum, resulting in lower PR of the $\mu \mathrm{m}$-Si panels during the winter season. During summer months, $\mu \mathrm{m}$-Si panels achieve higher performance thanks to the lower temperature coefficient and thermal annealing, leading to partial recovery from the Staebler-Wronski degradation mechanism.

\section{B. Effect of filtering on annual degradation rates}

The effect of the clipping filter on the PR data has been discussed above (see Fig. 4). However, such filtering can have a pronounced effect on the calculated degradation rates, as illustrated in Fig. 8. The difference between the unfiltered and filtered results obtained from PR data (bars) is statistically significant for each panel type, with the exception of a-Si. In all five cases, the filtering introduces a positive
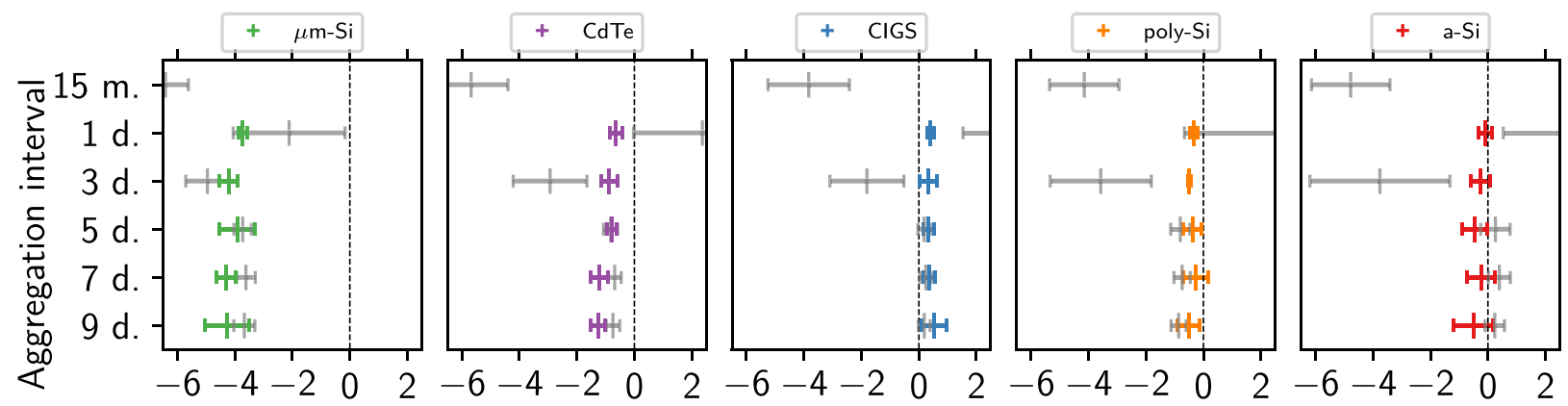

Annual degradation rate $/ \%$

FIG. 7. Effect of increasing aggregation time intervals on the degradation rates and on the $68 \%$ confidence intervals calculated from the measured unfiltered PR, based on the YoY averaging method and LSQ averaging (gray). 


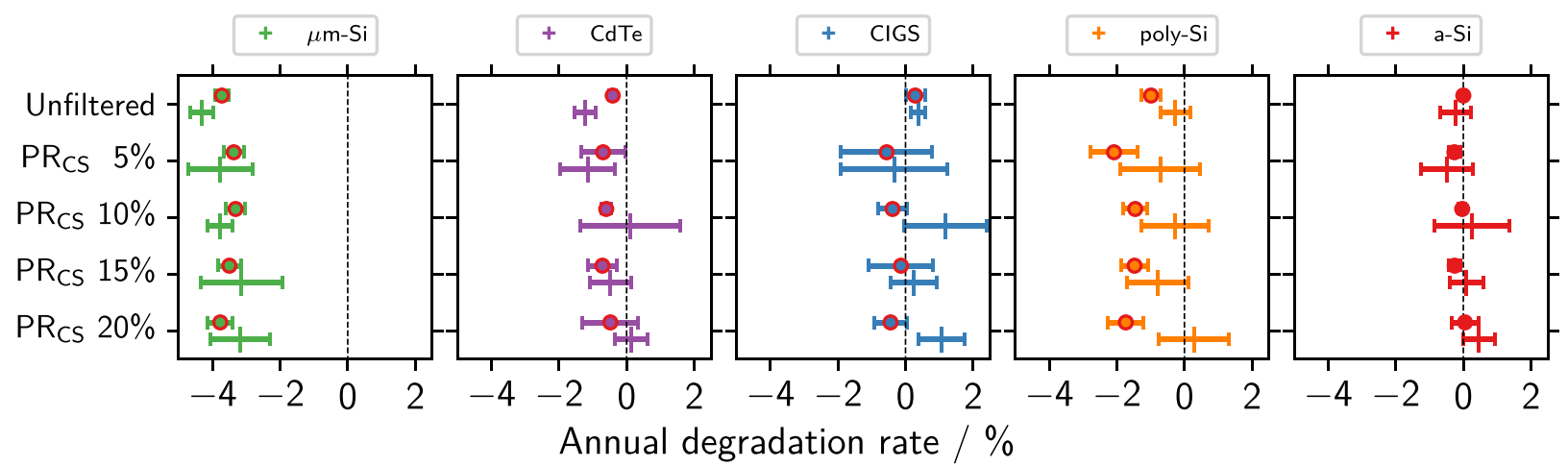

FIG. 8. Annual degradation rates for all five PV module types based on the unfiltered (top) and filtered data (bottom). Degradation rates based on PR (bars) and rPR (red circles) are shown with $68.2 \%$ confidence intervals as error bars. The results aggregated to 7 day intervals and fitted using YoY regression are shown.

bias into the degradation rates. In the case of CIGS and poly-Si panels, the resulting degradation rate is $\sim+2 \%$ annually, which would mean the performance of the panels improves significantly with time.

The restriction to a $200-1200 \mathrm{~W} \mathrm{~m}^{-2}$ window of solar irradiance has the biggest contribution to this positive shift compared to the other filtering masks. This can be explained by the particular type of pyranometer malfunction: when water droplets form on the glass dome, deflecting or concentrating sunlight, a randomized distribution of irradiance values is measured, and the $15 \mathrm{~min}$ PR is scattered around the true value. Due to this random nature of the distribution, the sensor malfunction is averaged out during the aggregation step. The irradiance mask of the clipping filter cancels out this self-correction effect, by excluding low PR values. This is a consequence of the filter removing irradiance values above $1200 \mathrm{~W} \mathrm{~m}^{-2}$ (see Fig. 4).

When $\mathrm{rPR}$ is used instead of PR (red circles in Fig. 8), the filtering step has only a minor effect on the degradation rates. Notably, the confidence intervals of the rPR-based data are also significantly smaller than those for the PR-based results. This is a further confirmation that the positive bias upon filtering of the PR data is caused by the unreliable pyranometer irradiance.

\section{Clear-sky filtering}

In order to circumvent issues related to unreliable temperature and irradiance and temperature sensor data, a methodology based on the calculation of a clear-sky performance ratio $\left(\mathrm{PR}_{\mathrm{cs}}\right)$ using modeled irradiance and temperature data was proposed by Jordan et al. ${ }^{19,21,22}$
In principle, the only measured data required for the calculation of $\mathrm{PR}_{\mathrm{cs}}$ are the power output of each panel type, while the solar irradiance and temperature values in Eq. (1) are replaced by the modeled values assuming clear-sky conditions. In practice, the modeled $\mathrm{PR}_{\mathrm{cs}}$ has to be normalized to an on-site reference. Here, we explore using the measured pyranometer irradiance $G$ as well as the irradiance derived from the a-Si power data $G_{\mathrm{a}-\mathrm{Si}}$. The clear-sky filter then ensures that only measured power values that agree with the modeled clear-sky conditions are used based on a required trust interval.

The effects of the trust interval in the clear-sky filter are shown in Fig. 9. For some panel types, such as the a-Si and $\mu \mathrm{m}-\mathrm{Si}$ panels, the degradation rates are consistent, regardless of whether PR or rPR data are used or which trust interval is applied in the clear-sky filter. Similar to the unfiltered data, the rPR results (red circle) have narrower confidence intervals than the PR-based degradation rates (bars).

The current dataset is insufficient to make clear conclusions about the trust intervals. A $10 \%$ trust interval results in very narrow confidence intervals with $\mathrm{rPR}$ data and very wide intervals with PR data. With a $15 \%$ trust interval, which is the default value in the rdtools-1.2.2 library, the confidence intervals of the rPR- and PRbased results overlap with each other as well as with the unfiltered data. The $20 \%$ trust interval recommended by Jordan et al. ${ }^{22}$ introduces a positive bias into the PR-based degradation rates for the CdTe, CIGS, poly-Si, and to a lesser extent the a-Si panels, while the rPRbased results are largely unaffected. On balance, the default trust interval of $15 \%$ is perhaps the most suitable choice.

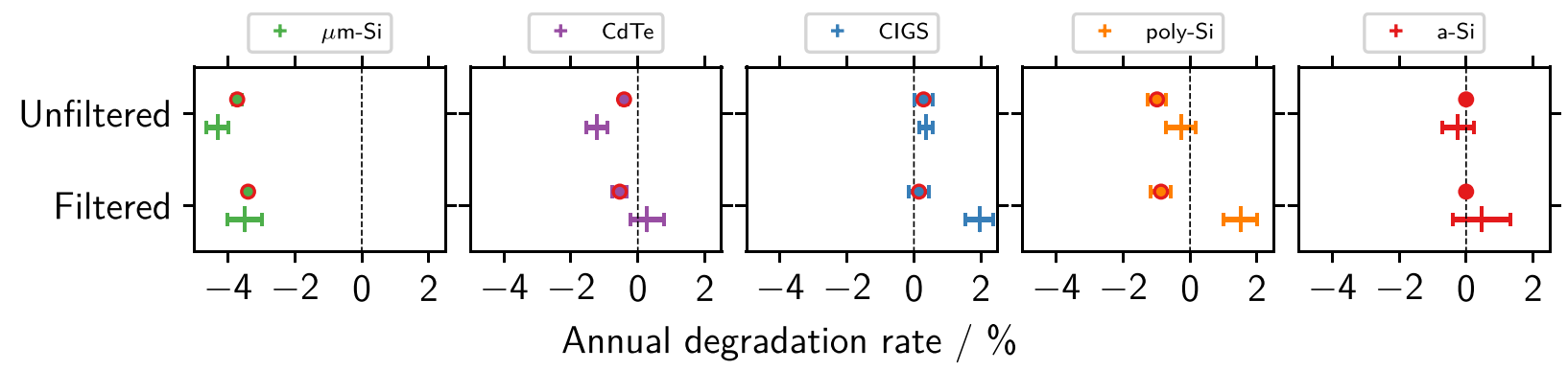

FIG. 9. The effect of the trust interval on the clear-sky annual degradation rates. Degradation rates based on PR (bars) and rPR (red circles) are shown with $68.2 \%$ confidence intervals as error bars. Unfiltered results are included for comparison. All the results aggregated to 7 day intervals and fitted using YoY regression are shown. 


\section{CONCLUSION}

Our study supports the call for the integration of real-world data to evaluate the aging of PV technology under field conditions. To facilitate this goal, all on-site performance data are made available in the supplementary material. While the degradation rates obtained in the current work cannot be taken as an indicator of the global performance of the respective technologies, the degradation performance of the poly- $\mathrm{Si}$, a-Si, and to a lesser extent CdTe panels was stable over the first 5 years. Jordan and $\mathrm{Kurtz}^{7}$ reported median annual degradation rates for modules installed after 2000 to be $-0.40 \%,-0.96 \%,-0.87 \%$, and $-0.64 \%$ for CdTe, CIGS, poly-Si, and a-Si modules, respectively. Elsewhere, Si-based panels were shown to have a median degradation rate of $-0.3 \%$ per annum in the first 3 years after installation, provided that they were installed on nonresidential properties. ${ }^{24}$ Our results for poly-Si and a-Si panels (see Table S1) are consistent with the previously published data, while the CdTe panels seem to perform worse than expected. On the other hand, the CIGS panels seem to be improving over the years: this phenomenon in the performance of commercial CIGS panels over several years has been reported before in the literature and is advertised by some manufacturers. ${ }^{21}$ On the other hand, the results obtained for the commercial $\mu \mathrm{m}$-Si panels confirm the concerns of rapidly degrading photovoltaic performance. The clear-sky methodology yields an annual degradation rate of $\sim-3.5 \%$ for this set of panels (see Table S2). This corresponds to a mean of $-17.7 \%$ over 5 years. Despite passing the standardized IEC 61646:2008, IEC 61730-1:2007, and IEC 61730-2:2007 performance tests, it is unclear whether the $\mu \mathrm{m}$-Si panels match the manufacturer's warranty, which guarantees $90 \%$ of minimum stabilized rated power output over the first 10 years. Deceglie et al. reported a significant increase in the degradation rates of panels after 6 years from installation. ${ }^{24}$ It will be interesting to see whether similar degradation trends can be observed at the Mülheim site in the near future.

The current work also shows that even in cases of serious sensor malfunction, reliable long-term performance assessment can be performed by applying robust aggregation and regression methods, as well as the clear-sky methodology developed at the NREL. The wide use of such standardized tools should be strongly advocated as the resulting performance datasets collected from research facilities from all over the world will be more reliable and can contribute to predictive models.

\section{SUPPLEMENTARY MATERIAL}

See the supplementary material for a pdf file, which includes (i) tables of degradation rates of all panel types, (ii) histograms of the YoY degradation rates for each panel type, and (iii) a figure showing the time evolution of the YoY degradation rate and a zip file, containing all primary data as well as the scripts required to reproduce figures in this manuscript.

\section{ACKNOWLEDGMENTS}

The authors gratefully acknowledge Bastian Zinser from BASTIZI for programming of the PV plant, Willi Schlaman for technical coordination at the institute, and Marius Podleska for the technical support and service. The authors also express their gratitude to Fachri Atamni, the Managing Partner from OFA Consulting $\mathrm{GmbH}$ and the architect Pilar Perez for the close collaborative work. We would also like to thank Horst Schaller and Martin Sturznikel for programming the website (https:// pv.cec.mpg.de). The authors particularly thank the companies, which sponsored the photovoltaic modules.

\section{REFERENCES}

${ }^{1}$ ASTM E2848-13, Standard Test Method for Reporting Photovoltaic NonConcentrator System Performance (ASTM International, West Conshohocken, PA, 2018).

${ }^{2}$ A. Louwen, A. C. de Waal, R. E. I. Schropp, A. P. C. Faaij, and W. G. J. H. M. van Sark, "Comprehensive characterisation and analysis of PV module performance under real operating conditions," Prog. Photovoltaics: Res. Appl. 25, 218-232 (2017).

${ }^{3}$ International Energy Agency, Trends 2018 in Photovoltaic Applications (International Energy Agency (IEA), 2018).

${ }^{4}$ S. Philipps and W. Warmuth, Photovoltaics Report (Fraunhofer ISE, 2019).

${ }^{5}$ R. W. Miles, K. M. Hynes, and I. Forbes, "Photovoltaic solar cells: An overview of state-of-the-art cell development and environmental issues," Prog. Cryst. Growth Charact. Mater. 51, 1-42 (2005).

${ }^{6}$ M. A. Green, Y. Hishikawa, E. D. Dunlop, D. H. Levi, J. Hohl-Ebinger, M. Yoshita, and A. W. Y. Ho-Baillie, "Solar cell efficiency tables (version 53)," Prog. Photovoltaics: Res. Appl. 27, 3-12 (2019).

${ }^{7}$ D. C. Jordan and S. R. Kurtz, "Photovoltaic degradation rates-An analytical review,” Prog. Photovoltaics: Res. Appl. 21, 12-29 (2013).

${ }^{8}$ C. Buerhop, D. Schlegel, C. Vodermayer, and M. Nieß, Quality Control of PVModules in the Field using Infrared-Thermography (EU PVSEC, 2011).

${ }^{9}$ M. Köntges, S. Kurtz, C. Packard, U. Jahn, K. Berger, K. Kato, T. Friesen, H. Liu, and M. Van Iseghem, Performance and Reliability of Photovoltaic Systems-Subtask 3.2: Review of Failures of Photovoltaic Modules (IEA, 2014).

${ }^{10}$ A. Raykov, H. Nagel, D. J. Amankwah, and W. Bergholz, Climate Model for Potential-Induced Degradation of Crystalline Silicon Photovoltaic Modules (EU PVSEC, 2012).

${ }^{11}$ J. Berghold, M. Roericht, A. Böttcher, S. Wendlandt, M. Hanusch, S. Koch, P. Grunow, and B. Stegemann, Electrochemical Corrosion within Solar Panels (EU PVSEC, 2012).

${ }^{12}$ C. Buerhop and J. Bachmann, "Infrared analysis of thin-film photovoltaic modules,” J. Phys.: Conf. Ser. 214(1), 012089 (2010).

${ }^{13} \mathrm{D}$. Staebler and C. Wronski, "Reversible conductivity changes in dischargeproduced amorphous Si," Appl. Phys. Lett. 31, 292-294 (1977).

${ }^{14}$ J. Meier, J. Spitznagel, U. Kroll, C. Bucher, S. Fay, T. Moriarty, and A. Shah, "Potential of amorphous and microcrystalline silicon solar cells," Thin Solid Films 451-452, 518-524 (2004).

${ }^{15}$ H. Keppner, J. Meier, P. Torres, D. Fischer, and A. Shah, "Microcrystalline silicon and micromorph tandem solar cells," Appl. Phys. A 69, 169-177 (1999).

${ }^{16}$ A. Shah, J. Meier, E. Vallat-Sauvain, C. Droz, U. Kroll, N. Wyrsch, J. Guillet, and U. Graf, "Microcrystalline silicon and 'micromorph' tandem solar cells," Thin Solid Films 403-404, 179-187 (2002).

${ }^{17}$ N. Strevel, L. Trippel, and M. Gloeckler, "Performance characterization and superior energy yield of first solar PV power plants in high-temperature conditions," Photovoltaics Int. 17, 7 (2012), available at https://www.pv-tech.org/ technical-papers/performance-characterization-and-superior-energy-yield-offirst-solar-pv-po.

${ }^{18} \mathrm{~T}$. Carlsson and A. Brinkman, "Identification of degradation mechanisms in field-tested CdTe modules,” Prog. Photovoltaics: Res. Appl. 14, 213-224 (2006).

${ }^{19} \mathrm{M}$. Theelen, V. Hans, N. Barreau, H. Steijvers, Z. Vroon, and M. Zeman, “The impact of alkali elements on the degradation of CIGS solar cells," Prog. Photovoltaics: Res. Appl. 23, 537-545 (2015).

${ }^{20} \mathrm{~J}$. Wohlgemuth, "IEC 61215: What it is and isn't (Presentation)," in PV Module Reliability Workshop (NREL, 2012).

${ }^{21}$ D. C. Jordan, S. R. Kurtz, K. VanSant, and J. Newmiller, "Compendium of photovoltaic degradation rates," Prog. Photovoltaics: Res. Appl. 24, 978-989 (2016).

${ }^{22}$ D. C. Jordan, C. Deline, S. R. Kurtz, G. M. Kimball, and M. Anderson, "Robust PV degradation methodology and application," IEEE J. Photovoltaics 8, 525-531 (2018). 
${ }^{23}$ W. Luo, Y. S. Khoo, P. Hacke, D. C. Jordan, L. Zhao, S. Ramakrishna, A. G. Aberle, and T. Reindl, "Analysis of the long-term performance degradation of crystalline silicon photovoltaic modules in tropical climates," IEEE J. Photovoltaics 9, 266-271 (2019).

${ }^{24}$ M. G. Deceglie, D. C. Jordan, A. Nag, A. Shinn, and C. Deline, "Fleet-scale energy-yield degradation analysis applied to hundreds of residential and nonresidential photovoltaic systems," IEEE J. Photovoltaics 9, 476-482 (2019).

${ }^{25}$ E. Hasselbrink, M. Anderson, Z. Defreitas, M. Mikofski, Y. Shen, S. Caldwell, A. Terao, D. Kavulak, Z. Campeau, and D. DeGraaff, "Validation of the PVLife model using 3 million module-years of live site data," in 2013 IEEE 39th Photovoltaic Specialists Conference (PVSC) (2013).

${ }^{26}$ D. C. Jordan, M. G. Deceglie, and S. R. Kurtz, "PV degradation methodology comparison-A basis for a standard," in 2016 IEEE 43rd Photovoltaic Specialists Conference (PVSC) (2016).

${ }^{27}$ NREL, https://www.nrel.gov/pv/rdtools.html for Accurate degradation rate calculation with RdTools; accessed February 15, 2019.

${ }^{28}$ N. Aste, C. Del Pero, and F. Leonforte, "PV technologies performance comparison in temperate climates," Sol. Energy 109, 1-10 (2014). 